\title{
Spatio-temporal water body and vegetation changes in the Nile swamps of southern Sudan
}

\author{
G. Petersen ${ }^{1}$, J. A. Abeya ${ }^{2}$, and N. Fohrer ${ }^{3}$ \\ ${ }^{1}$ HR Wallingford Ltd, Howbery Park, Wallingford, Oxon, OX10 8BA, UK \\ ${ }^{2}$ World Agroforestry Centre (ICRAF), United Nations Avenue, Gigiri, P.O. Box 30677-00100 GPO, Nairobi, Kenya \\ ${ }^{3}$ Christian-Albrechts-University of Kiel, Ecology Centre, Department of Hydrology and Water Resources Management, \\ Olshausenstr. 75, 24118 Kiel, Germany
}

Received: 15 January 2007 - Revised: 4 April 2007 - Accepted: 22 May 2007 - Published: 20 June 2007

\begin{abstract}
An assessment to describe and quantify the extent of changes in the channel and lagoon system of the Sudd was carried out using Landsat satellite images of 1973, 1979, 1997 and 2002. Using supervised classification and visual interpretation after referencing the images, the water bodies for a representative area between Bor and Shambe (a stretch of $150 \mathrm{~km}$ ) were delineated. The resulting files were compared to establish and quantify changes in-between the years and as well compared to Lake Victoria outflow data to assess a likely correlation which was found for the largely water level dependent lagoon system. Changes in the channel system were interpreted to happen in a certain pattern but the extent of changes could not be correlated to the outflow data as they are influenced by other, here not considered factors like wind drift and channel blockages by vegetation.
\end{abstract}

\section{Introduction}

The Nile swamps of southern Sudan, called the Sudd, one of the largest wetland areas in Africa (Mohamed, 2005), represent a highly dynamic system (Butcher, 1938), in which channels, lagoons and inundated areas are constantly interacting and changing in time and space. An aerial overview of typical swamp is given in Fig. 1. Swamp processes for the Sudd region in general have been described by different authors, e.g. Butcher (1938), Hurst (1932, 1933), Migahid (1948) Mefit-Babtie (1983), Sutcliffe $(1957,1974)$ and Sutcliffe and Parks (1999), while the extent of changes have so far not been quantified. Water levels and flow velocities interact with vegetation species which in return have an influence on the channel dynamics. Channel blockages by vegetation cause impounding of areas and increased flow elsewhere, wind drift results in movement of floating reed fields.
The main objective of this paper is to describe and quantify the extent of changes in the channel and lagoon system of the Sudd over a period of 30 years. A representative area of the swamps between Bor and Shambe was evaluated in detail regarding the changes which have occurred between 1973 and 2002. The results have been related to the hydrodynamic situation of the period, allowing the assessment of the general trend and behavior of the system in which the meandering channels, moving reed fields and frequent blockages cause challenges for researchers as well as for the economic development of the area.

\section{Methods}

For the evaluation of the channel and lagoon changes, an analysis of geo-referenced Landsat MSS, TM and ETM band 1/2/3 images (NASA, 2007) of 1973, 1979, 1997 and 2002 for the southern Sudd area between Bor and Shambe as shown in Fig. 2 has been carried out, comparing and quantifying the changes in open water bodies. A panchromatic combination of band 1,2 and 3, represented as blue, green and red was used for the current analysis based on a sensitivity analysis where combinations of the different bands were tested for their suitability to provide optimum results. Classification of the channel and lagoon features was then carried out using supervised classification method based on visual interpretation of the images. To assure comparable datasets, images from comparable seasons were selected for the evaluation. Despite the 1973 data which was acquired in February, October images were used for the data evaluation. Possible misinterpretation was eliminated using supervised classification method; matching georeference of the images acquired by the different Landsat sensors was assured by overlaying the images and testing them for their conformity.

Correspondence to: G. Petersen

(g.petersen@hrwallingford.co.uk)

Published by Copernicus Publications on behalf of the European Geosciences Union. 


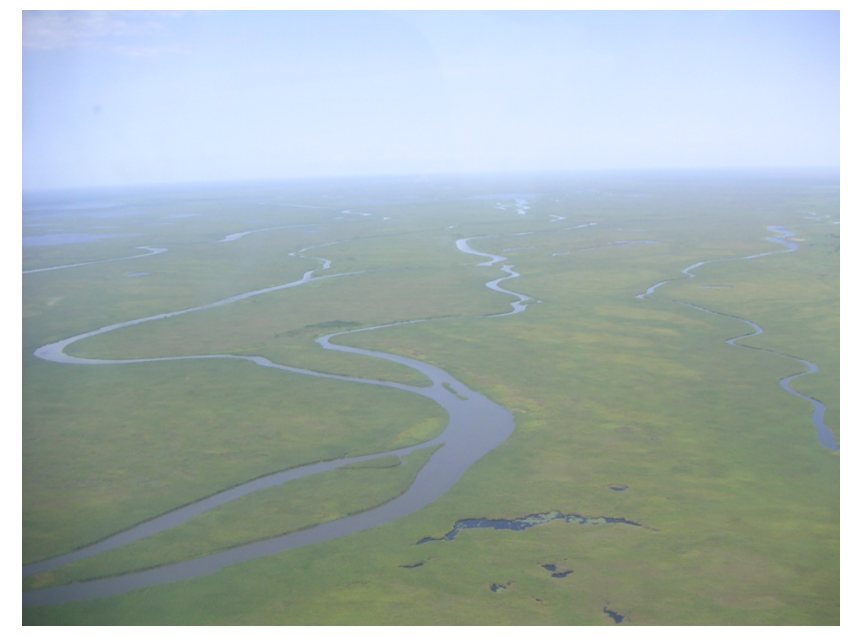

Fig. 1. Aerial photograph of the permanent swamp area with channels, lagoons, floating and anchored vegetation areas, taken during an aerial assessment in 2004 over the swamps near Baidit/Padak.

\section{The system}

To understand the driving forces of the system, the flow regime as well as the role of the vegetation needs to be understood.

Vegetation cover in the Sudd swamps can generally be classified depending on the elevation of the area above river flood level (Hurst and Phillips, 1938) as

- permanent swamp

- river flooded grasslands (Toic)

- rain flooded grasslands

- wooded grasslands (acacia)

- woodlands

Vegetation types are generally distributed in accordance to flooding depth and duration with Lake Vicoria outflow being the controlling factor (Migahid, 1948).

The lake discharge is contributing the base flow entering the swamps, superimposed by torrential runoff during the rainy season and therefore controlling the water levels. The permanent swamp area is mainly inhabited by Cyperus $p a$ pyrus, Typha domingensis and Vossia cuspidata, while the seasonally river-flooded grasslands are inhabited by Oryza longistaminata and Echinochloa pyramidalis. Echornia crassipes is another species which is increasingly dominating the lagoons. While detailed vegetation maps were not available, it can be assumed that vegetation type and their distribution has changed in concordance with the changes in hydrologic regime over the years.

The vegetation distribution is described in further detail by Sutcliffe (1974); the main species are shown in Table 1. The

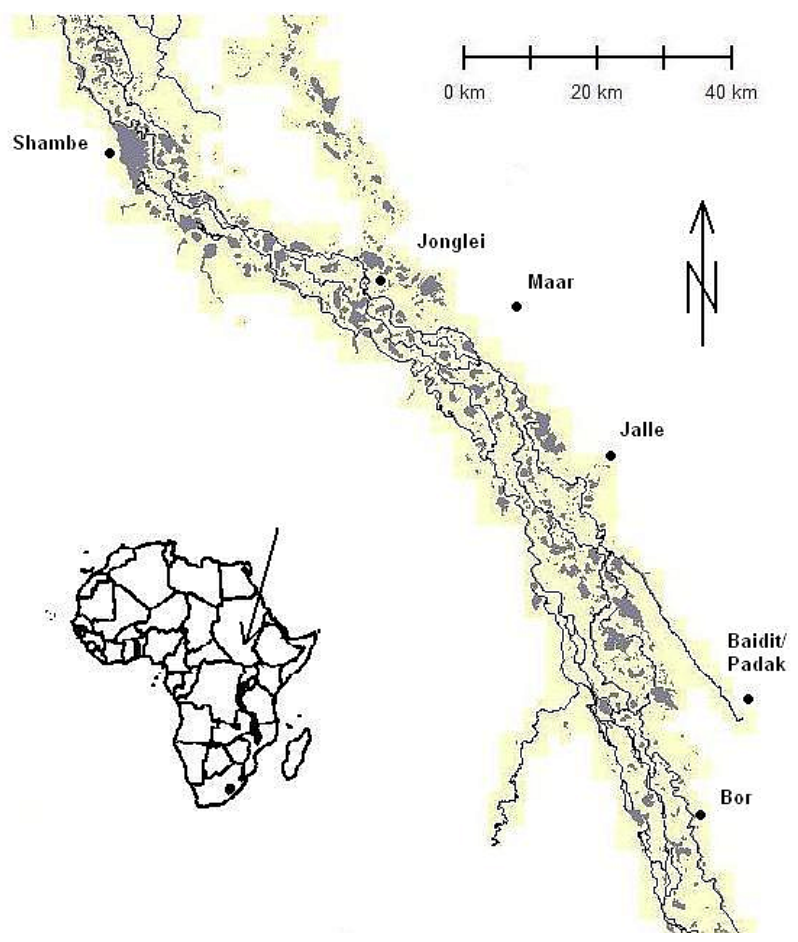

Fig. 2. Area overview map derived from Landsat image interpretation showing the channel and lagoon system as well as the extent of the permanent swamp area.

first three species are anchored so their distribution is limited to depth of flooding, for the last three species their root system needs to be in water or saturated soil permanently which gives a good indicator on changing flood patterns. Phragmites communis, Echinochloa pyramidalis and Oryza barthii for example dominate only in areas where the depth of flooding does not exceed $130 \mathrm{~cm}$ over a period of ten years or $118 \mathrm{~cm}$ for a month in the year. Cyperus papyrus needs saturated conditions, can tolerate deep flooding but is limited to a certain range of flooding which appears to be $150 \mathrm{~cm}$ (Sutcliffe, 1974). Increasing flood levels will cause these plants to be dislodged from their position and floating downstream which may cause channel blockages. Also reports of Euroconsult (1981) describe the phenomenon of channel blockages which can further on be proven by aerial observation and Landsat satellite image evaluation where the lighter green shade of newly grown reeds in blocked river channels is distinguishable from the darker green of older vegetation.

\section{Results}

The evaluation of the datasets shows that the main channel system is stable; channels generally decrease in width and move in an upstream direction as shown in Fig. 3. The significant trends can mainly be observed at bends and along straight channel sections, where the channel movements 
Table 1. Main species inhabiting the Sudd swamps after data from JIT (1954).

\begin{tabular}{llll}
\hline Species & Use & Flooding depth & Roots \\
\hline Phragmites communis & (grazing) & shallow $(\max 130 \mathrm{~cm})$ & buried \\
Echinochloa pyramidalis & (grazing) & shallow $(\max 130 \mathrm{~cm})$ & buried \\
Oryza barthii & (grazing) & shallow $(\max 130 \mathrm{~cm})$ & buried \\
Echinochloa stagnina & & deep & superficial/floating \\
Vossia cuspidate & & deep & superficial/floating \\
Cyperus papyrus & & deep & superficial/floating \\
\hline
\end{tabular}

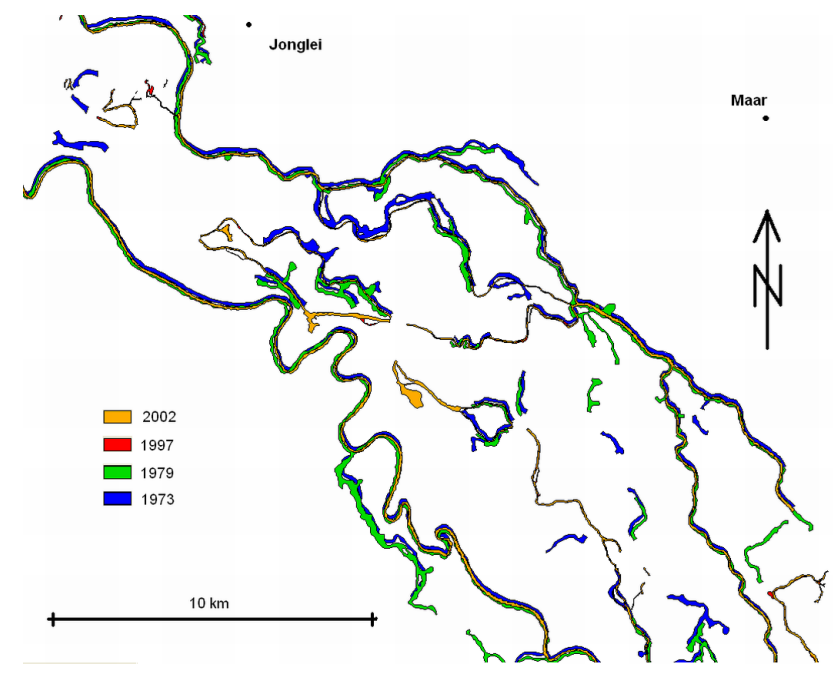

Fig. 3. Overlaid channel system of the years 1973, 1979, 1997 and 2002 of the area of Maar - Jonglei, indicatively showing the general trends of channel movements and decrease in channel width.

exhibit a typical pattern by moving outward between 1973 and 1979 and then again slightly inward between 1979 and 1997/2002. Movements can be quantified with up to $200 \mathrm{~m}$ over the 30 year period of investigation. No significant trends can be observed between the 1997 and 2002 datasets where changes are erratic and do not follow a defined pattern.

Lagoons show a different trend, with the location of the main lagoons being stable in location but showing a tendency of decreasing in size as visible in Fig. 4, a phenomenon which correlates with the decreasing Lake Victoria outflows during the period of investigation leading to lower water levels followed by an increase of vegetation growth in the now habitable areas with less water depth. For the area of investigation between Bor and Shambe the area of open water bodies decreased by $38 \%$ in surface area between 1973 and 2002. The Shambe lagoon as an example decreased in size from $30.4 \mathrm{~km}^{2}$ to $27.0 \mathrm{~km}^{2}$ in surface area. A decrease in channel width, considering the main channels over the same period is quantified with $34 \%$, e.g. for the main channels at Jonglei latitude from $97 \mathrm{~m}$ to $74 \mathrm{~m}$ in width in average. Movement of channel boundaries is thereby significant so that errors which

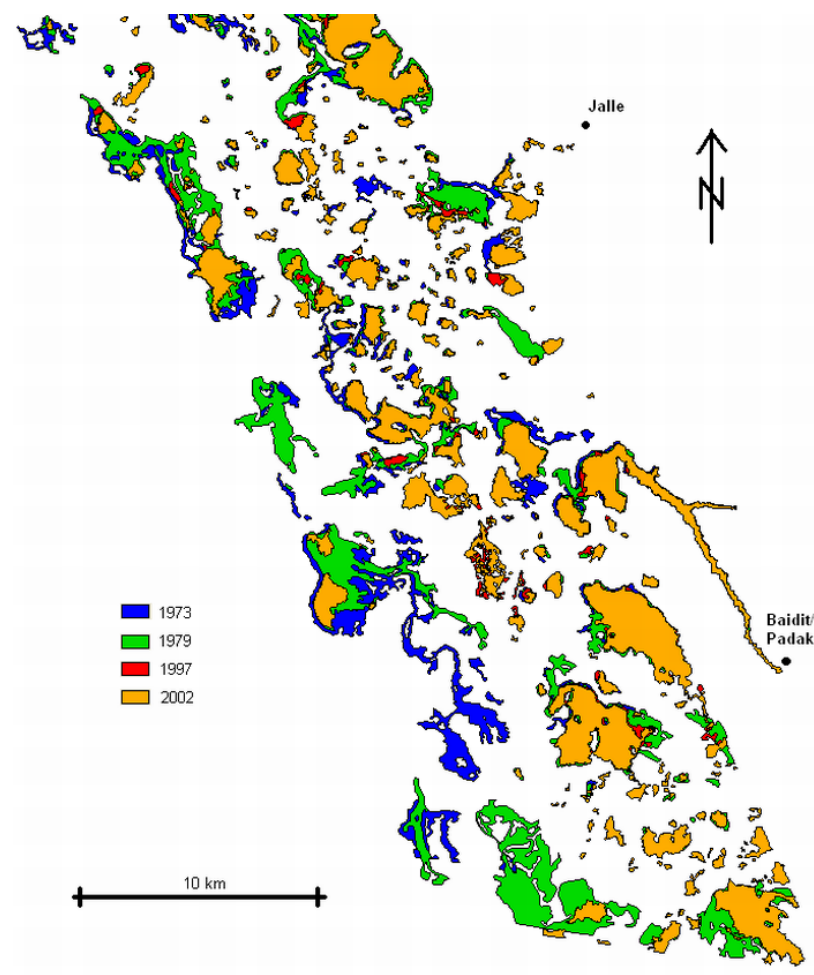

Fig. 4. Overlaid lagoon system of the years 1973, 1979, 1997 and 2002 of the Padak - Jalle area indicating the decrease in lagoon area.

may have been introduced during data acquisition and processing can be neglected.

Evaluation of channel changes in relation to extreme flow events considering the different conditions between the investigated points in time leads to no clear trend. 1973 data shows the situation after average flow conditions as shown in Fig. 5. The following 1979 data pictures the situation after the 1978 high flow conditions with the respective high flood levels, the situation until 1997 then shows average to below average flow conditions, while in 1998 another peak event was recorded. Evaluating the spatial datasets in respect to these flow conditions as shown in Fig. 5 does not yield a significant relation to these. A clear linear relation of changes 


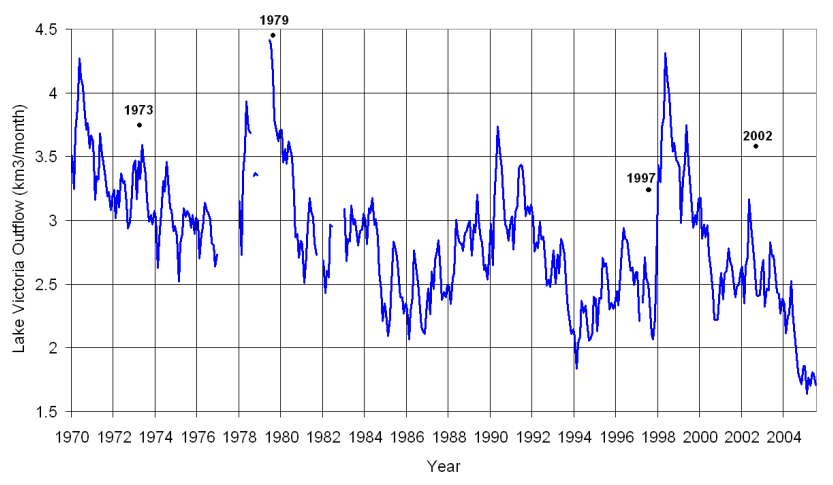

Fig. 5. Lake Victoria outflow at Jinja (after data from Hurst, 1933 and supplements) with marked years of evaluated satellite data.

of the swamp system to the described flow conditions can therefore not be deduced as flow events are not matching with the observed changes in the channel system. It needs to be assumed that other factors like e.g. wind drift and channel blockages as well as long term effects play a significant superimposing role as well.

\section{Discussion}

An assessment was carried out to describe and quantify the extent of changes in the channel and lagoon system of the Sudd between 1973 and 2002. Results show clear trends of channel movements with time while no linear correlation can be established to Lake Victoria outflows. Lagoon sizes and channel width on the other hand show a decreasing trend, which in general matches with the decreasing lake outflow, a finding that corresponds with the fact that swamp vegetation is water level dependent and that more swamp area becomes habitable for cyperus papyrus with decreasing water levels.

The factor that a correlation could be established for the lagoon and channel sizes but not for the channel movements is assumed to be related to the more complex range of factors influencing channel movements which have not been captured in the assessment. As described by Koponen and Kummu (2004), channel blockages can have large impacts on local water levels and other factors like wind drift have been observed to have a significant influence on the floating reed fields. Varying combinations of these short term factors - general discharge related water levels, current velocities, wind drift and blockage related water level changes therefore randomly alter the system not allowing for a general prediction of magnitudes of changes. As a trend, but not in linear correlation to the discharges, a general downstream movement of the channels is visible from image interpretation, the movements at the bends being of greater magnitude than along the straight channel sections, a fact assumably caused by increased erosion forces along the outsides of the bends as it can generally be observed in meandering river systems.

\section{Conclusions and future perspective}

Spatio-temporal water body changes in the Sudd swamps of southern Sudan can be captured and evaluated and quantified using Landsat satellite data. Correlation between lagoon size and lake discharge is established, while channel changes can not be directly related to Lake Victoria outflow. For a detailed assessment of the channel changes, next to the factors as described above, also ground referenced vegetation maps in fine spatial resolution would be needed as the type of vegetation is, also concerning the ground level it indicates in the swamps, of significant importance for a detailed assessment of channel changes.

Edited by: K.-E. Lindenschmidt

Reviewed by: B. Guse and an anonymous referee

\section{References}

Butcher, A. D.: The Sadd Hydraulics, Government Press, Cairo, 1938.

Euroconsult: Kongor Flood Protection Surveys, Draft Final Report, Arnhem, 1981.

Hurst, H. E.: The Nile Basin, Volume IV and Supplements 1-13, Ten Day Mean and Monthly Mean Discharges of the Nile and its Tributaries, Cairo, 1933.

Hurst, H. E. and Phillips, P.: The Nile Basin, Volume V, The Hydrology of the Lake Plateau and the Bahr el Jebel, Schindler Press, Cairo, 1938.

JIT: The Equatorial Nile Project and its Effects on the AngloEgyptian Sudan, Volumes I-IV, Sudan Government, Khartoum, 1954.

Koponen, J. and Kummu, M.: Support to the Management of Sudd Blockage on Lake Kyoga, ILM-EIAC, Finland, 2004.

Mefit-Babtie Srl: Development Studies of the Jonglei Canal Area, Range Ecology Survey, Final Report, Volume 2, Background, Khartoum, 1983.

Migahid, A. M.: Report on a Botanical Excursion to the Sudd Region, University Press, Cairo, 1948.

Mohamed, Y. A.: The Nile Hydroclimatology: Impact of the Sudd Wetland, PhD Dissertation, Delft University of Technology, Netherland, 2005.

NASA: The Landsat Program, http://landsat.gsfc.nasa.gov, 2007.

Sutcliffe, J. V.: The Hydrology of the Sudd Region of the Upper Nile, PhD Thesis, Cambridge University, Cambridge, 1957.

Sutcliffe, J. V.: A Hydrological Study of the Southern Sudd Region of the Upper Nile, Hydrol. Sci. Bulletin XIX, 2, 6/1974, 237255, 1974.

Sutcliffe, J. V. and Parks, Y. P.: The Hydrology of the Nile, IAHS Special Publication No. 5, Wallingford, 1999. 